\title{
High flow nasal cannula to prevent intubation in obese patient with COVID-19 induced ARDS: a case report
}

\author{
Ni Made Ayu Suria Mariati ${ }^{1,2}{ }^{*}$, Adhrie Sugiarto ${ }^{1}$, Elya Endriani ${ }^{2}$, Rina Lestari ${ }^{3}$, Karina Anindita ${ }^{4}$ \\ Author affiliations: \\ 1- Department of Anesthesiology \& Intensive Care, Faculty of Medicine, Universitas Indonesia, Jakarta, Indonesia. \\ 2- Department of Anesthesiology \& Intensive Care, Faculty of Medicine, University of Mataram-West Nusa Tenggara \\ General Hospital, Lombok, Indonesia. \\ 3- Pulmonology Department, Faculty of Medicine, University of Mataram-West Nusa Tenggara General Hospital, Lombok, \\ Indonesia. \\ 4- Department of Internal Medicine, Siloam Hospitals Mataram, Jl. Majapahit, Pagesangan, Kec. Mataram, Kota \\ Mataram, Nusa Tenggara Bar. 83115, Indonesia.
}

Correspondence: Ni Made Ayu Suria Mariati, Trainee in Intensive Care, Department of Anesthesiology \& Intensive Care, Faculty of Medicine, Universitas Indonesia, Jl. Salemba Raya No.6, RW.5, Kenari, Kec. Senen, Kota Jakarta Pusat, Daerah Khusus Ibukota Jakarta 10430, Indonesia. E-mail: suriamariati@yahoo.com; Mobile: +62 81338720329

\section{Abstract}

Obese patients have been identified to have a poor prognosis and a higher risk of death from coronavirus disease2019 (COVID-19). We present reports of two obese patients infected with COVID-19 with acute respiratory distress syndrome (ARDS) who showed improvement with high flow nasal cannula (HFNC). HFNC is a noninvasive oxygen delivery device which is capable of delivering a high concentration of oxygen that can reduce the requirement for tracheal intubation. HFNC is convenient to use, can reduce dyspnea without effecting the length of stay in ICU in these cases; and has a high merit to be used in selected patients requiring oxygen before attempting intubation and mechanical ventilation.

Key words: ARDS; COVID-19; High flow nasal cannula; HFNC; Obese

Citation: Mariati NMAS, Sugiarto A, Endriani E, Lestari R, Anindita K. High flow nasal cannula to prevent intubation in obese patient with COVID-19 induced ARDS: a case report. Anaesth pain intensive care 2021;25(2):212-216. DOI: 10.35975/apic.v25i2.1473

Received: 18 November 2020, Reviewed: 24 November 2020, Accepted: 7 December 2020

\section{Introduction}

The coronavirus, first identified in Wuhan City, China, causing coronavirus disease (COVID-19) in December 2019, is the Severe Acute Respiratory Syndrome Coronavirus-2 (SARS-CoV-2). ${ }^{1-4}$ The outbreak spread rapidly in China, northern Italy, Europe, and in most of the countries of the world. WHO declared the outbreak of COVID-19 as a pandemic on March 12, 2020. ${ }^{5}$
The prognosis of COVID-19 has been known to be adverse in old age and in patients with comorbid conditions, such as hypertension, cardiovascular disorders, diabetes mellitus, and pulmonary diseases. ${ }^{1,6,7}$ Nonetheless, in the younger population, a higher rate of hospital admission has been documented and associated with obesity. Globally, the increased prevalence of obesity has raised concerns about its deleterious effects on the pandemic. ${ }^{7}$ WHO has 
described both the outbreak of COVID-19 and the 'epidemic of obesity' as a global public health emergency. Global observations in clinical and epidemiological terms indicate that in individuals with obesity-related disorders, corona viruses cause more serious symptoms and complications. ${ }^{8}$

Excessive weight and obesity are characterized as fat deposits that are abnormal or disproportionate and pose a potential health risk. Obesity significantly increases the risk of a person having multiple noncommunicable diseases (NCDs), including cardiovascular disease, cancer, and diabetes. ${ }^{2,3}$ Furthermore, prolonged hospital stay and high admission rate in intensive care units (ICUs) also correlated with higher morbidity and mortality rates in obese patients compared to average weight populations. ${ }^{2,5}$

Obesity and morbid obesity have been recognized in many reviews as risk factors for hospital admission, mechanical ventilation, and higher mortality from earlier respiratory viral pandemics, e.g. the 2009 H1N1 influenza, ${ }^{3,6,8}$ due to a compromised immune system, increasing the individual's susceptibility to infection. $^{7}$ The Centers for Disease Control and Prevention (CDC) recognized severe obesity (i.e., $\mathrm{BMI} \geq 40 \mathrm{~kg} / \mathrm{m} 2$ ) as a common clinical contributing factor for even worse prognosis and higher mortality in patients with COVID-19. Even in patients with COVID-19, any level of obesity (BMI $>30 \mathrm{~kg} / \mathrm{m}^{2}$ ) has been linked to poor prognosis. ${ }^{6,7}$

This case study provides evidence that overweight/obese individuals are most vulnerable to severe COVID-19, need oxygen support, survive, but with a long period of ICU admission. It highlight the usefulness of high flow nasal cannula (HFNC) in this set of patients in avoiding the need of intubation and mechanical ventilation.

\section{Case report-1}

Our first case, a 55-year-old, obese man from the coastal area of the Lombok Island with BMI 40.1 $\mathrm{kg} / \mathrm{m} 2$, had a history of nonproductive cough for a week. RT-PCR on nasopharyngeal samples was positive with a SARS-CoV-2. He was transferred to our facility for further management. In the emergency department (ED), he had no fever, but complained of generalized weakness, cough, and dyspnea. Blood pressure was $128 / 88 \mathrm{mmHg}$, heart rate of 88 beats/min, respiratory rate 20 breaths/min, and oxygen saturation of $90 \%-92 \%$ with oxygen $10 \mathrm{~L} / \mathrm{min}$ through face mask. There were bilateral rales on auscultation of the lung fields.

At the time of hospital admission there was no leukocytosis, except mild neutrophilia (82.7\%) and lymphopenia (11.9\%). Platelet count was normal. Creactive protein was increased $(91 \mathrm{mg} / \mathrm{L})$, D-dimer reached $0.9 \mathrm{mg} / \mathrm{L}$, and procalcitonin was $1.1 \mathrm{ng} / \mathrm{mL}$. Unfortunately, interleukin-6 testing was not available in our hospital. He presented with severe ARDS (PaO2 $98 \mathrm{mmHg}, \mathrm{SpO} 297 \%$ with oxygen $10 \mathrm{~L} / \mathrm{min}$, PF ratio less than $\square$ 100) and showed bilateral basal interstitial pattern on chest x-ray (Figure 1). Consequently, he was transferred to the intensive care unit (ICU) where he received $100 \% \mathrm{O} 2$ at $60 \mathrm{~L} / \mathrm{min}$ through HFNC. He was put on levofloxacin $750 \mathrm{mg}$ daily, azithromycin $500 \mathrm{mg}$ daily, oseltamivir $75 \mathrm{mg}$ twice daily, and chloroquine phosphate $500 \mathrm{mg}$ twice daily for the first three days, continued $250 \mathrm{mg}$ twice daily for the next day until day 10 course, in. ascorbic acid $1 \mathrm{~g}$ IV daily, and low molecular weight heparin $1 \mathrm{mg} / \mathrm{kg}$ were administered subcutaneously twice a day as prophylaxis for thrombotic events.

On the second day, he showed worsening on chest $\mathrm{x}$ ray (Figure 2). The blood gas analysis showed $\mathrm{PaO} 2$ $88 \mathrm{mmHg}$, SO2 $97 \%$ with $90 \% \mathrm{FiO} 2$ at $60 \mathrm{~L} / \mathrm{min}$ through HFNC, PF ratio $<100$. Due to severe ARDS, the decision was made to administer convalescent plasma, discontinue oseltamivir, and start remdesivir with a loading dose of $200 \mathrm{mg}$, continued $100 \mathrm{mg}$ per day. He was also given methylprednisolone loading dose $80 \mathrm{mg}$ and continued on $40 \mathrm{mg}$ for 7 days, and famotidine $40 \mathrm{mg}$. After administering convalescent plasma, clinical improvement was seen and we could wean the HFNC. However, remdesivir was discontinued on day 7 due to raised levels of alanine and aspartate aminotransferase; ALT 294 IU/1 (normal range 7 to $55 \mathrm{U} / \mathrm{L}$ ), AST $294 \mathrm{U} / \mathrm{I}$ (normal range 5 to $40 \mathrm{U} / \mathrm{L})$ versus ALT $75 \mathrm{U} / \mathrm{L}$, AST 45 before remdesivir administration.

On day 8, the patient developed arrhythmia and hypotension, so azithromycin was stopped, and he was given anti-arrhythmic and vasopressors.

On day 9, chloroquine phosphate was discontinued due to persistent arrhythmia. 
On day 11, an escalation was noted, vancomycin was given based on the result of the blood culture, also given anti-fungal micafungin $50 \mathrm{mg}$ a day. On day 14, he fully weans from high flow nasal cannula and vasopressor, also a nasopharyngeal swab analyzed by RT-PCR was negative.

On day 17 , he was transferred to the ward. He was discharged from the hospital on day 23 .

\section{Case Report-2}

A 38 years old man with obese $\left(40,4 \mathrm{~kg} / \mathrm{m}^{2}\right)$ presented with fever, cough, and shortness of breath for seven days. He also complained of diarrhea, lost sense of taste, and smell for 3 days. At the time of hospital admission, the patient's respiratory frequency was 20 with oxygen saturation of $90 \%-91 \%$ on room air, blood pressure $109 / 55 \mathrm{mmHg}$, without fever.
Laboratory results showed no leukocytosis $(6.300 / \mathrm{uL})$, without neutrophilia (61\%), or lymphopenia (26\%). Ddimer reached $510 \mathrm{ng} / \mathrm{mL}$. The RAPID test was nonreactive on IgM or IgG-anti SARS-CoV-2 but a nasopharyngeal swab analyzed by RT-PCR confirmed a SARS- CoV-2 infection. Electrolyte results, sodium $133,5 \mathrm{mmol} / \mathrm{L}$, potassium 3,35 mmol/L, and chloride 93,1 mmol/L. Blood gas analysis presented severe ARDS $\left(\mathrm{PaO}_{2}=121 \mathrm{mmHg} ; \mathrm{SO}_{2} 98,9 \%\right.$, simple mask oxygen $15 \mathrm{~L} / \mathrm{min}, \mathrm{PF}$ ratio $<150$ ), and the $\mathrm{X}$-ray showed bilateral involvement, infiltrate in para hilar and paracardial, typical pneumonia (Figure 3). He was transferred to the intensive care unit where he received HFNC $60 \mathrm{~L} / \mathrm{min}, 100 \%$ oxygen fraction.

He was initiated on treatment with intravenous levofloxacin in a dose of $750 \mathrm{mg}$ every day, oseltamivir $75 \mathrm{mg}$ twice daily, chloroquine phosphate
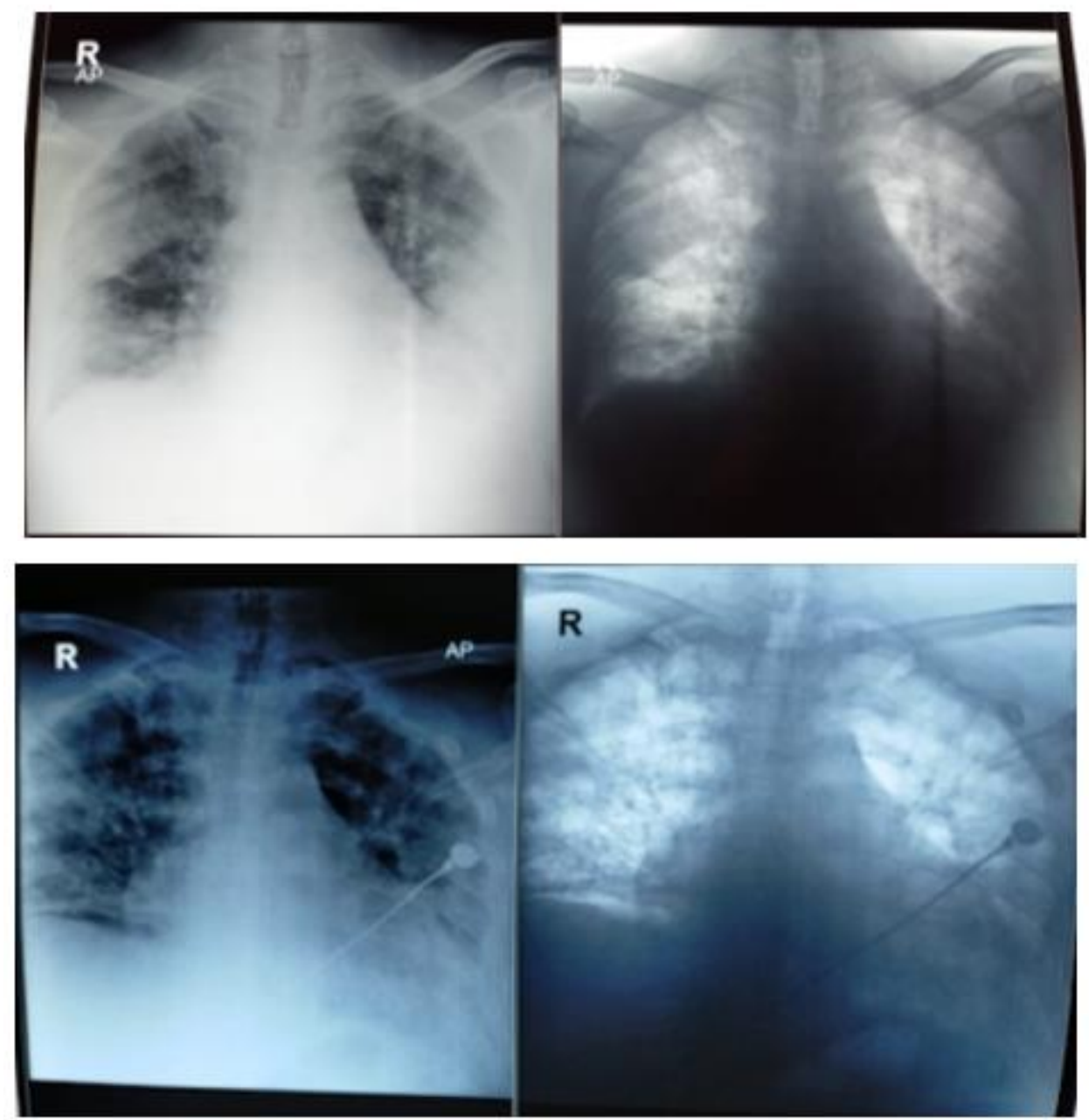

Figure 2: Chest $\mathrm{x}$-ray of the first patient on the second day showed worsening compared to Figure 1 
$500 \mathrm{mg}$ twice daily for the first three day, continued $250 \mathrm{mg}$ twice daily for the next day until day 10 course, without any adverse event. Unfractionated heparin 5000 IU twice daily was administered subcutaneously as prophylaxis for prothrombotic events. Dexamethasone $5 \mathrm{mg}$ twice a day, and vitamin C 1 gram once a day. On the third day he shown improvement, HFNC was weaned off. His oxygen saturation improved and dyspnea relieved over the next four days. On day 9, the patient was stable and did not require oxygen therapy. The patient showed improvement in his general condition, and on day 11 of his hospitalization, which was more than 14 days from the onset of symptoms, he was considered clinically recovered and was discharged with followup as an outpatient basis.

\section{Discussion}

Here, we describe two cases of obese patients with SARS-CoV-2 infection in Lombok, Indonesia. The clinical management, therapy, and progression of both cases that allowed for COVID-19 recovery are described. Critical status assessment, clinical oxygen management by the nasal cannula for mild and moderate cases of invasive/noninvasive mechanical ventilation for severe cases were included in the standard of care for patients with COVID-19 in our hospital upon admission. Choosing the appropriate devices for oxygen administration is one of the key decisions faced by healthcare professionals.

Obese patients often experience physiological respiratory impairment and increased risk of pneumonia, pulmonary hypertension, and cardiac stress associated with hypoventilation. Severe obesity is also associated with sleep apnea syndrome, surfactant dysfunction, and insufficient glucose control (due to reduced ventilatory function); these are the factors which contribute to a poor prognosis. ${ }^{5}$ Obese patients have more fat around neck tissue that can make intubation more difficult. ${ }^{1}$ They are subjected to longer intubation periods and are difficult to wean off mechanical ventilation. ${ }^{5}$ Considering the risks of intubation and invasive ventilation, the role of noninvasive ventilation (NIV) in patients with acute respiratory failure has been investigated in several studies. ${ }^{9,10}$ HFNC is a noninvasive device, that is capable of delivering a high concentration of oxygen

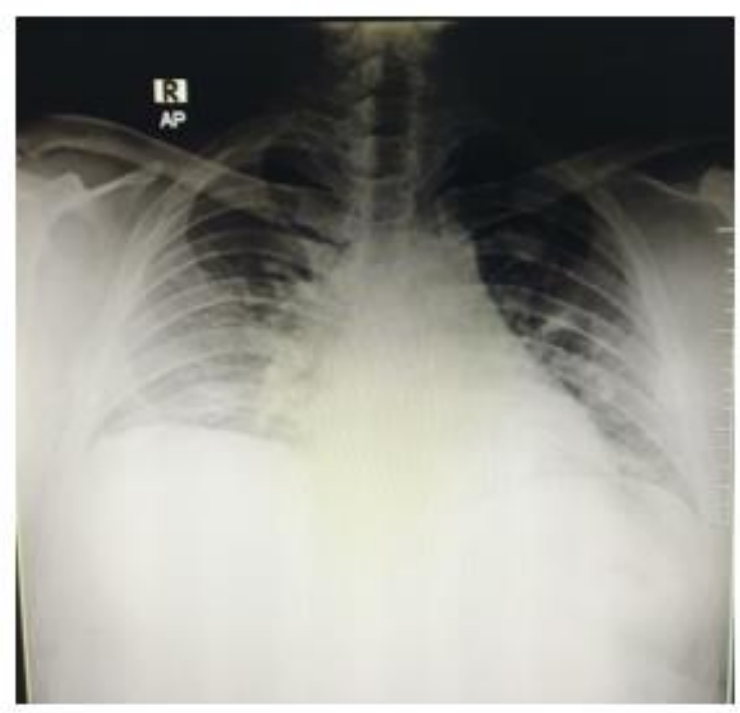

Figure 3: Chest $x$-ray second patient, showed bilateral involvement, infiltrate in para hilar and paracardial, typical pneumonia.

that can overcome the limitations of conventional NIV. ${ }^{10}$ In our reported cases, acute respiratory failure triggered by COVID-19 was promptly treated by high flow nasal oxygenation (HFNO) and showed improvement. There is a lot of debate about the use of HFNO in COVID-19, concerning the benefits and the harms in terms of the patients or the healthcare workers. Comparison of HFNO with conventional oxygen therapy in patients with acute hypoxemic respiratory failure through systematic review and meta-analysis, nine RCTs involving 2093 patients found no difference in mortality in those treated with HFNO (relative risk (RR) 0.94, 95\% CI 0.67-1.31) versus those receiving conventional oxygen therapy. HFNO reduced the need for tracheal intubation (RR 0.85, 95 percent CI 0.74-0.99) and decreased the risk of escalation through supplemental oxygen (RR 0.71, 95 percent CI 0.51-0.98) compared with other conventional therapy. ${ }^{10}$

The massive outbreak caused by the novel coronavirus has shown the virulence of the virus that directly impacts the world's global health system. A high demand for treatment areas for prolonged periods, particularly ICUs and human resources experienced in intensive care, can lead to the exhaustion of the health systems. ${ }^{5}$ The use of HFNC may decrease the need for tracheal intubation in our patients with acute 
hypoxemic respiratory failure. In a patient who is given HFNC, the risk of fatigue may occur, so its use should be supervised and reconsidered if it does not show improvement within a few hours. HFNC did not affect patient comfort, dyspnea, or ICU/hospital length of stay in these cases.

\section{Competing Interests}

All authors have full access to all the data, take full responsibility for the accuracy of the data, and have took part in the management of the case and preparation of the manuscript.

\section{Authors" contribution}

ASM: Study concept, prepare the manuscript and manuscript editing

AS, EF, EE, RL, KA: Manuscript editing

\section{References}

1. Caci G, Albini A, Malerba M, Noonan DM, Pochetti P, Polosa R. COVID-19 and obesity: dangerous liaisons. J Clin Med. 2020;9(8):2511. [PubMed] DOI: 10.3390/jcm9082511

2. Dafallah Albashir AA. The potential impacts of obesity on COVID-19. Clin Med. 2020;20(4):e109-13. [PubMed] DOI: 10.7861/clinmed.2020-0239

3. Malik VS, Ravindra K, Attri SV, Bhadada SK, Singh M. Higher body mass index is an important risk factor in COVID-19 patients: a systematic review and metaanalysis. Environ Sci Pollut Res Int. 2020 Nov;27(33):42115-42123. [PubMed] DOI: 10.1007/s11356-020-10132-4
4. Villani ER, Carfi A, Di Paola A, Palmieri L, Donfrancesco $C$, Lo Noce $C$, et al. Clinical characteristics of individuals with Down syndrome deceased with COVID-19 in Italy-A case series. Am J Med Genet A. 2020 Dec;182(12):2964-2970. [PubMed] DOI: 10.1002/ajmg.a.61867

5. de Siqueira JVV, Almeida LG, Zica BO, Brum IB, Barceló $A$, de Siqueira Galil AG. Impact of obesity on hospitalizations and mortality, due to COVID-19: A systematic review. Obes Res Clin Pract. 2020 SepOct;14(5):398-403. [PubMed] DOI: 10.1016/i.orcp.2020.07.005

6. Sanchis-Gomar F, Lavie CJ, Mehra MR, Henry BM, Lippi G. Obesity and outcomes in COVID-19: when an epidemic and pandemic collide. Mayo Clin Proc. 2020;95(7):1445-53. [PubMed] DOI: 10.1016/j.mayocp.2020.05.006

7. Tamara A, Tahapary DL. Obesity as a predictor for a poor prognosis of COVID-19: A systematic review. Diabetes Metab Syndr. 2020 Jul-Aug;14(4):655-659. [PubMed] DOI: $10.1016 /$ i.dsx.2020.05.020

8. Petrakis D, Margină D, Tsarouhas K, Tekos F, Stan M, Nikitovic D, et al. Obesity - a risk factor for increased COVID-19 prevalence, severity, and lethality (Review). Mol Med Rep. 2020;22(1):9-19. [PubMed] DOI: 10.3892/mmr.2020.11127

9. Lyons $\mathrm{C}$, Callaghan $\mathrm{M}$. The use of high-flow nasal oxygen in COVID-19. Anaesthesia. 2020;75(7):843-7. [PubMed] DOI: 10.1111/anae.15073

10. Rochwerg B, Granton D, Wang DX, Helviz Y, Einav S, Frat JP, et al. High flow nasal cannula compared with conventional oxygen therapy for acute hypoxemic respiratory failure: a systematic review and metaanalysis. Intensive Care Med. 2019;45(5):563-72. [PubMed] DOI: $\underline{10.1007 / \mathrm{s} 00134-019-05590-5}$ 